\title{
MODEL AHP/DEA UNTUK MENGUKUR EFISIENSI PENGGUNAAN TEKNOLOGI GAS BUANG RUMAH TANGGA RAMAH LINGKUNGAN
}

\author{
Parwadi Moengin \\ Lab. Sistem dan Simulasi Industri, \\ Gedung F/G Jurusan Teknik Industri, Universitas Trisakti \\ J1. Kyai Tapa, Grogol Jakarta 11440 Telp: 021-5663232 ext 407, Fax: 021-5605841 \\ parwadi@trisakti.ac.id
}

\begin{abstract}
Abstrak
Dalam makalah ini diperkenalkan sebuah model AHP/DEA untuk mengukur efisiensi penggunaan teknologi gas buang rumah tangga ramah lingkungan. Model ini merupakan sebuah model yang mengintegrasikan antara AHP dan DEA yang merupakan salah satu dari metode multi-criteria decision making (MCDM). Metode ini merupakan salah satu prosedur saintifik yang dapat digunakan untuk mengukur penggunaan teknologi gas ramah lingkungan.
\end{abstract}

Kata kunci: AHP, DEA, teknologi gas ramah lingkungan.

\section{Abstract}

This paper introduced a model of AHP / DEA to measure the efficiency of the use of exhaust gas technology environmentally friendly household. This model is a model that integrates the AHP and DEA, which is one of the methods of multi-criteria decision making (MCDM). This method is a scientific procedure that can be used to measure the use of environmentally friendly gas technologies.

Keywords: AHP, DEA, environmentally friendly gas technologies.

\section{PENDAHULUAN}

Belum lama ini, Pemerintah Indonesia menetapkan Rencana Nasional untuk Pengembangan Teknologi Energi. Rencana Nasional tersebut bertujuan untuk meningkatkan intensitas energi, mengurangi emisi gas buang rumah tangga ke level standar yang digariskan dalam the United Nations Framework Convention on Climate Change (UNFCCC), dan berkontribusi terhadap pertumbuhan ekonomi Indonesia. Rencana baru ini juga mempertimbangkan kondisi melambungnya harga minyak dunia, the United Nations Framework Convention on Climate Change (UNFCCC), dan kedatangan sebuah era baru yang dinamakan ekonomi hidrogen.

Dalam makalah ini, digunakan pendekatan Analytic Hierarchy Process (AHP) dan model Data Envelopment Analysis (DEA) untuk menentukan bobot preferensi relatif teknologi gas buang rumah tangga ramah lingkungan. Analytic Hierarchy Process (AHP) adalah sebuah metode subyektif yang digunakan untuk menganalisis kriteria kualitatif untuk memberi bobot sebuah unit operasi. Saaty pertama kali mengusulkan AHP sebagai sebuah metode pengambilan keputusan yang dapat digunakan untuk menyelesaiakn masalah tak terstruktur tahun 1977 [3]. Secara umum, Saaty mengindikasikan bahwa pengambilan keputusan melibatkan perencanaan [4], pembangkitan sekumpulan alternatif, penentuan prioritas [2], pemilihan kebijakan terbaik dari sekumpulan alternatif, pengalokasian sumber daya, penentuan kebutuhankebutuhan, prediksi hasil, perancangan sistem, pengukuran performansi, menjamin stabilitas sistem, serta optimasi dan resolusi konflik [5].

Saaty memperkenalkan empat prinsip AHP, yaitu dekomposisi, prioritasisai, sintesis dan sensitivitas. Dalam AHP, proses pengambilan keputusan dimodelkan setelah struktur hirarki dibuat. Pada setiap level hirarki, pembuat keputusan diharuskan untuk membuat perbandingan berpasangan di antara alternatif-alternatif 
keputusan dan membuat kriteria dengan menggunakan skala rasio untuk membobot atribut. AHP menentukan rangking atau prioritas relatif dari alternative keputusan.

DEA adalah sebuah prosedur analitik yang didasarkan pada pemrograman matematika yang telah dikembangkan oleh Charnes et al. (1978) yang digunakan untuk mengukur efisiensi relatif dari unit-unit pengambilan keputusan atau decision making unit (DMU) dalam sebuah kumpulan. DEA ini digunakan untuk menilai efisiensi relatif dari DMU. Sekali efisiensi pengembangan teknologi energy telah dievaluasi, sebuah DMU kemudian diklasifikasikan sebagai efisien atau tidak efisien.

Dalam makalah ini, AHP digunakan untuk menentukan bobot kriteria dan alternatif dalam rencana gas buang rumah tangga ramah lingkungan. Setelah itu, bobot relatif diterapkan pada data yang digunakan untuk mengukur efisiensi metode DEA. Kajian ini menyajikan secara ringkas mengenai model AHP/DEA yang digunakan untuk menentukan prioritas teknologi energi untuk rencana gas buang rumah tangga ramah lingkungan. Hasil yang diperoleh dengan model AHP/DEA ini tidak hanya menyediakan sebuah alat pengambilan keputusan bagi pemerintah, tetapi juga menyajikan sebuah konsensus pakar dalam sektor perencanaan gas rumah tangga ramah lingkungan.
Akhirnya makalah ini disusun menggunakan urutan sebagai berikut. Dalam Sub bab 2 dijelaskan metodologi yang digunakan dalam makalah ini yang terdiri dari metode AHP dan DEA, serta diagram alir metodologi. Hasil (contoh numerik) dan pembahasan disajikan di dalam sub bab 3 dan 4 . Sub bab 5 merupakan kesimpulan dari makalah ini.

\section{METODOLOGI}

\section{Diagram Alir Metodologi}

Diagram alir metodologi disusun dalam 6 tahap seperti ditunjukkan dalam Gambar 1. Tahap pertama adalah menganalisis kebijakan energi, lingkungan energi dan daftar singkat mengenai teknologi gas buang rumah tangga. Tahap kedua adalah perumusan kriteria yang digunakan untuk menentukan bobot kepentingan relatif kriteria dan alternatif.

Pada tahap 3, menentukan struktur dan kriteria yang digunakan. Pada tahap 4, menentukan prioritas teknologi energi dengan menggunakan proses AHP. Efisiensi teknologi gas rumah tangga ramah lingkungan dievaluasi dengan menggunakan pendekatan DEA, yang dilakukan pada tahap 5. Akhirnya nilai efisiensi yang dihasilkan dalam tahap 5 dievaluasi dalam tahap 6 .

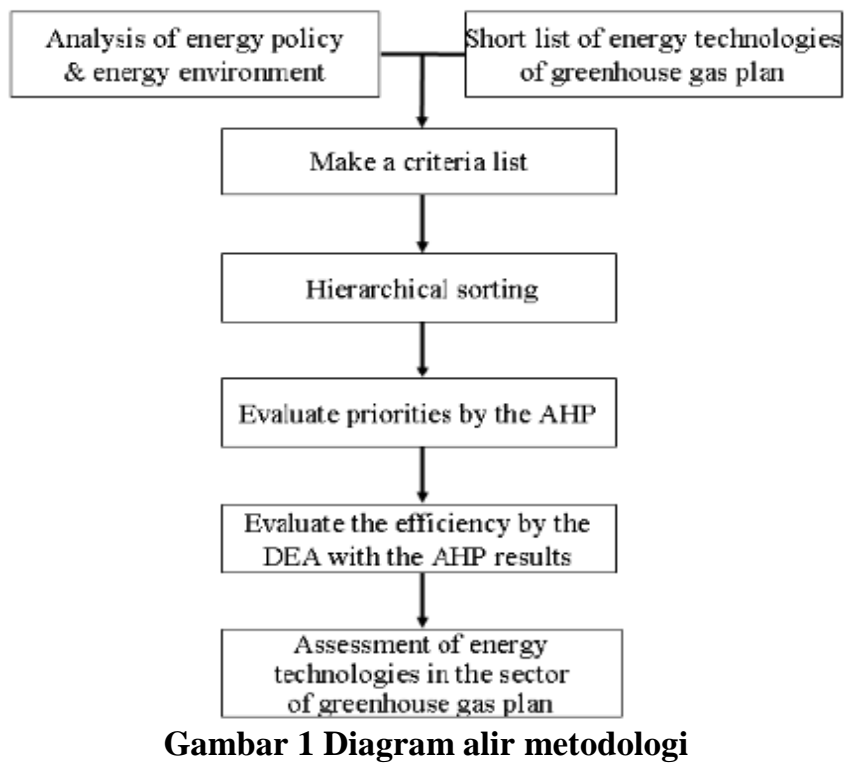

J@TI Undip, Vol VIII, No 1, Januari 2013 


\section{Metode AHP}

AHP memungkinkan seorang pengambil keputusan untuk menstrukturkan suatu masalah kompleks menjadi sebuah bentuk hirarki sederhana dan kemudian mengevaluasi sejumlah besar faktorfaktor kuantitatif dan kualitatif dengan kriteria ganda. AHP menggunakan matriks perbandingan berpasangan, struktur hirarki dan skala rasio untuk membobot atribut. Seperti ditunjukkan dalam Gambar 2, masalah didekomposisikan menjadi hirarki goal, atribut dan alternatif menggunakan proses AHP. Kriteria, alternatif dan hirarki distrukturkan dalam fase ketiga, kemudian digunakan untuk menguraikan masalah kompleks menjadi sejumlah elemen dalam sebuah bentuk hirarki. Fase keempat mengevaluasi apakah hirarki telah didasarkan pada target dan telah disusun dengan benar. Sebuah peer-review dilakukan pada tahap 5 . Matriks perbandingan berpasangan dilakukan pada tahap 6 , kemudian bobot kriteria dihitung dan diperiksa konsistensinya pada tahap 7 dan tahap 8 . Pada tahap 9 sebuah review rasio konsistensi atau consistency ratio (CR) dilakukan untuk menjamin bahwa CR terletak di antara 0 dan 0,1. Akhirnya bobot keseluruhan teknologi gas buang rumah tangga digunakan dalam model DEA.

Tabel 1 menunjukkan skala perbandingan berpasangan. Bilangan 1, 3, 5, 7 dan 9 digunakan sebagai skala rasio yang berhubungan dengan kekuatan preferensi untuk satu elemen terhadap elemen yang lain. Kemampuan untuk membuat perbedaan kualitatif dinyatakan dengan 5 kemungkinan pilihan yaitu equal, moderate, strong, very strong, dan extreme, seperti ditunjukkan oleh Tabel 1.

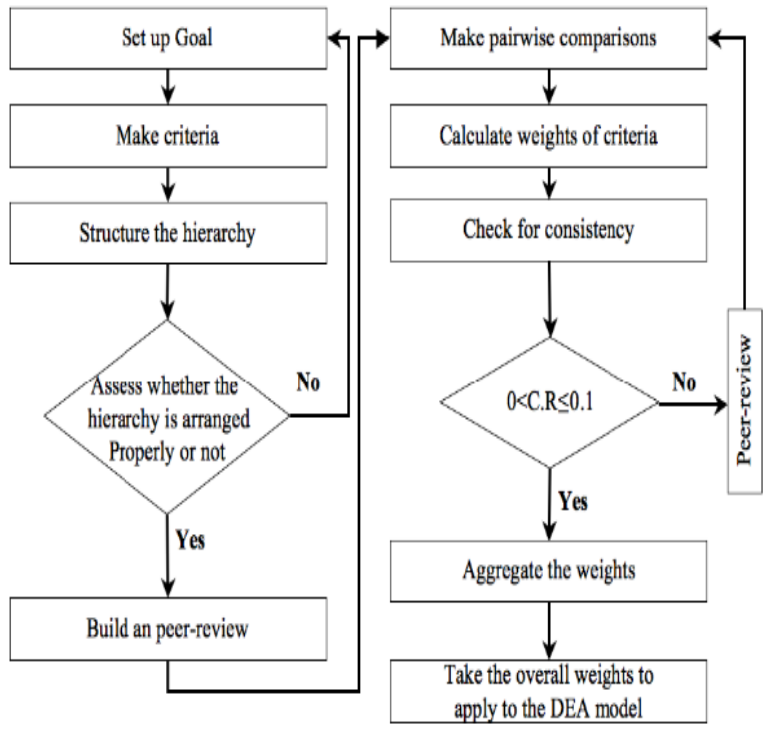

Gambar 2 Proses AHP

Tabel 1 Skala perbandingan berpasangan

\begin{tabular}{|c|c|c|}
\hline $\begin{array}{l}\text { Importance } \\
\text { scale }\end{array}$ & Definition & Explanation \\
\hline 1 & $\begin{array}{l}\text { Equal } \\
\text { importance }\end{array}$ & Two elements contribute \\
\hline 3 & $\begin{array}{l}\text { Moderate } \\
\text { importance }\end{array}$ & $\begin{array}{l}\text { One element is slightly } \\
\text { favored over another }\end{array}$ \\
\hline 5 & $\begin{array}{l}\text { Strong } \\
\text { importance }\end{array}$ & $\begin{array}{l}\text { One element is strongly } \\
\text { favored over another }\end{array}$ \\
\hline 7 & $\begin{array}{l}\text { Very strong } \\
\text { importance }\end{array}$ & $\begin{array}{l}\text { One element is very } \\
\text { strongly favored over } \\
\text { another }\end{array}$ \\
\hline 9 & $\begin{array}{l}\text { Extreme } \\
\text { importance }\end{array}$ & $\begin{array}{l}\text { One element is the most } \\
\text { favored over another }\end{array}$ \\
\hline
\end{tabular}

Persamaan berikut ini digunakan untuk menetukan bobot alternatif secara keseluruhan.

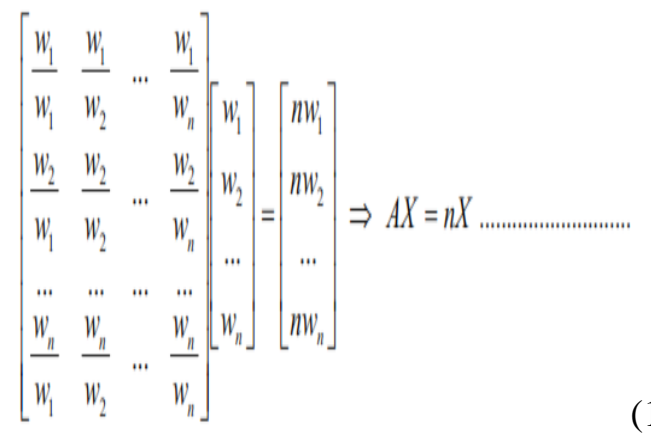


Jika matriks A bukan vektor taknol, maka ada suatu $\lambda$ max sehingga $A x=\lambda$ max, yang adalah vektor eigen terbesar dari matriks A. Jika matriks perbandingan berpasangan konsisten, maka $\lambda=\mathrm{n}$ dan $\mathrm{CR}$ $=0$. Untuk setiap alternatif, Consistency Ratio ditentukan dengan rasio Consistency Index (CI) terhadap Random Index (RI). Rumus berikut ini digunakan untuk menghitung nilai CI. Nilai CI juga disajikan dalam Tabel 2.

$$
\begin{gathered}
C I=\frac{\lambda_{\max }-n}{n-1} \\
C R=\frac{C I}{R I} \ldots . .
\end{gathered}
$$

Tabel 2. Random index

\begin{tabular}{cccc}
\hline Matrix index & RI value & Matrix index & RI value \\
\hline 1 & 0 & 6 & 1,24 \\
2 & 0 & 7 & 1,32 \\
3 & 0,58 & 8 & 1,41 \\
4 & 0,9 & 9 & 1,45 \\
5 & 1,12 & 10 & 1,49 \\
\hline
\end{tabular}

Kriteria AHP disusun atas 2-tier hierarchy. Struktur hirarki kriteria ditunjukkan oleh Gambar 3. Pada hirarki teratas, goal adalah untuk menentukan bobot kepentingan beberapa teknologi energi dalam rencana gas buang rumah tangga nasional. Ada 5 kriteria pada Level 1, yaitu UNFCCC, economical spin-off, technical spin-off, urgency of technology development, dan quantity of energy use. Sedangkan Level 2 disusun atas 5 sub-kriteria yaitu possibility of developing technologies, potential quantity of energy savings, market size, investment benefit, dan ease of energy use.

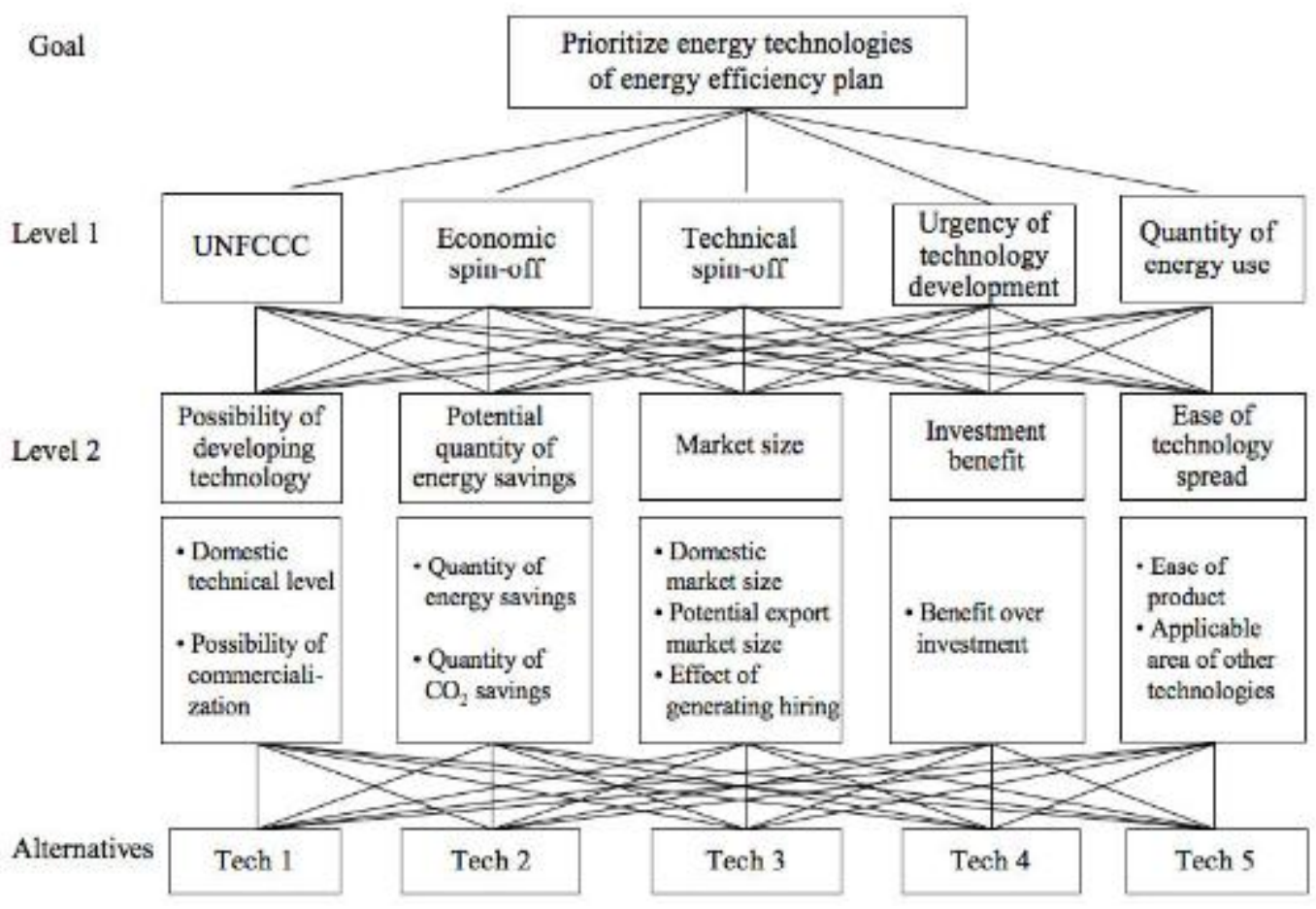

Gambar 3 Struktur hirarki AHP 


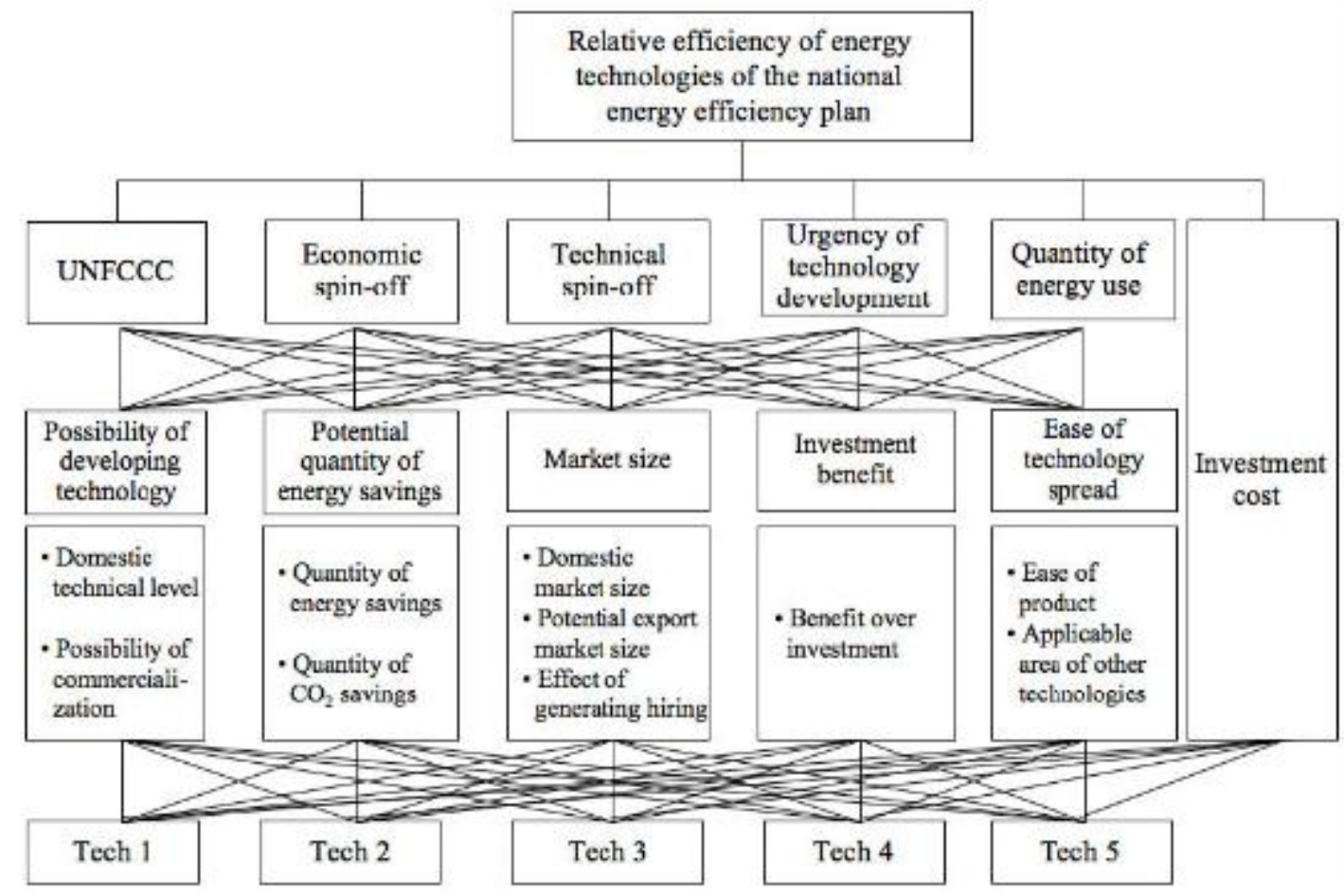

Gambar 4. Struktur hirarki DEA

\section{Model DEA}

Data Envelopment Analysis (DEA) adalah sebuah alat evaluasi yang terkait dengan decision making units (DMU) yang secara efektif dapat menyelesaikan beberapa masalah pengambilan keputusan yang secara simultan mengintegrasikan input dan output. Gambar 4 di atas menunjukkan struktur hirarki proses DEA yang terdiri dari sebuah input dan banyak output. Faktor input berupa biaya investasi pengembangan teknologi gas buang rumah tangga. Ada empat output, yaitu possibility of developing technology, potential quantity of energy savings, market size, investment benefit, dan ease of technology spread. Bobot relatif dihitung dengan menggunakan pendekatan AHP, kemudian bersamasama dengan factor output digunakan sebagai bagian dari pendekatan DEA.

Model DEA yang diusulkan oleh Charnes, Cooper and Rhodes (1978) [1], dirancang untuk mengukur efisiensi relative atau produktivitas DMUk. Misalkan ada n DMU yang dianalisis, yang masing-masing menggunakan

J@TI Undip, Vol VIII, No 1, Januari 2013 $m$ input dan $s$ output. Selanjutnya misalkan $\mathrm{k}(\mathrm{k}=1, \ldots, \mathrm{n})$ adalah DMU yang mana efisiensi relatif atau produktivitasnya dimaksimumkan.

Max $h_{k}=\frac{\sum_{r=1}^{s} u_{r k} Y_{r k}}{\sum_{j=}^{m} v_{i k} X_{i k}} \ldots$

Dengan kendala

$$
\begin{aligned}
& \frac{\sum_{r=1}^{s} u_{i k} Y_{r k}}{\sum_{i=1}^{m} v_{i k} X_{i k}} \leq 1, \text { untuk } \mathrm{j}=1,2, \ldots, \mathrm{n} \\
& u_{i k}>0, \text { untuk } \mathrm{r}=1,2, \ldots, \mathrm{s} \\
& v_{i k}>0, \text { untuk } \mathrm{i}=1,2, \ldots, \mathrm{m} . \\
& Y_{\mathrm{ij}}, X_{i \mathrm{j}}>0, \text { untuk semua i, j, dan r... }
\end{aligned}
$$

Dalam model DEA tersebut, menggunakan notasi sebagai berikut:

$u_{\mathrm{ik}}=$ variabel bobot yang diberikan kepada output $r$ dari DMU $k$

$v_{\text {ik }}=$ variabel bobot yang diberikan kepada input $r$ dari DMU $k$

$u_{\mathrm{k}} \mathrm{dan} v_{\mathrm{k}}=$ variabel keputusan yang menentukan efisiensi relative $\mathrm{DMU}$

$Y_{\mathrm{ij}}=$ output $r$ dari DMUj

$X_{i j}=$ input $i$ dari DMUj.

Dalam model DEA tersebut hk adalah efisiensi relatif nilainya terbesar 1 . Jika $h$ $\mathrm{k}=1$, DMUk

dikatakan sebagai sebuah efficient frontier. 
Tabel 3 Data input dan output

\begin{tabular}{lcccccc}
\hline Teknolgi & $\begin{array}{c}\text { Possibility of } \\
\text { developing tech }\end{array}$ & $\begin{array}{c}\text { Potential quantity of } \\
\text { energy savings }\end{array}$ & $\begin{array}{c}\text { Market } \\
\text { size }\end{array}$ & $\begin{array}{c}\text { Investment } \\
\text { benefit }\end{array}$ & $\begin{array}{c}\text { Ease of } \\
\text { energy use }\end{array}$ & $\begin{array}{c}\text { Investment } \\
\text { cost }\end{array}$ \\
\hline CO2 capture dan Conversion tech & 0,212 & 0,213 & 0,207 & 0,166 & 0,185 & 157 \\
Nan-CO2 gas technology & 0,105 & 0,104 & 0,110 & 0,151 & 0,132 & 58 \\
Advanced combustion techinology & 0,068 & 0,049 & 0,080 & 0,093 & 0,083 & 94 \\
Next-generation clean coal tech & 0,101 & 0,106 & 0,109 & 0,107 & 0,102 & 272 \\
Clean petroleum \& conversion tech & 0,073 & 0,069 & 0,061 & 0,059 & 0,064 & 94 \\
DME techinology & 0,087 & 0,084 & 0,074 & 0,075 & 0,084 & 84 \\
GTL technology & 0,079 & 0,092 & 0,081 & 0,077 & 0,074 & 84 \\
Gas hydrate & 0,062 & 0,071 & 0,065 & 0,060 & 0,065 & 84 \\
GHG mitigation policy & 0,042 & 0,042 & 0,042 & 0,042 & 0,042 & 47 \\
\hline
\end{tabular}

\section{CONTOH NUMERIK}

Pendekatan AHP digunakan untuk menentukan bobot relatif kriteria dan alternatif sebagai nilai input dan output yang digunakan untuk mengukur efisiensi relatif penggunaan teknologi gas buang rumah tangga ramah lingkungan menggunakan pendekatan DEA. Seperti ditunjukkan pada Tabel 3, penggunaan AHP menghasilkan output ganda berupa: possibility of developing technology, potential quantity of energy savings, market size, investment benefit, dan ease of technology used; serta input tunggal berupa biaya investasi sebagai bagian dari pendekatan DEA. Biaya investasi dinyatakan jutaan US dolar pada 2005.

Hasil dari pendekatan DEA dirangkum pada Tabel 4. Nilai efisiensi 1.000 berarti bahwa DMU tersebut (dalam hal ini Non$\mathrm{CO} 2$ gas tech) memberikan efisiensi tertinggi, dan dikelompokkan ke dalam sebuah kelompok efisiensi frontier. Kemudian diikuti oleh $\mathrm{CO} 2$ capture storage dan conversion technology, GTL technology, dan DME technology.

Tabel 4 Nilai efisiensi DEA

\begin{tabular}{lcc}
\hline Teknolgi & Nilai Efisiensi & Rangking \\
\hline CO2 capture dan Conversion technology & 0,7534 & 2 \\
Non-CO2 gas technology & 1,0000 & 1 \\
Advanced combustion technology & 0,4411 & 7 \\
Next-generation clean coal technology & 0,2152 & 9 \\
Clean petroleum dan conversion technology & 0,4264 & 8 \\
DME technology & 0,5692 & 4 \\
GTL technology & 0,6061 & 3 \\
Gas hydrate & 0,4724 & 6 \\
GHG mitigation policy & 0,4995 & 5 \\
\hline
\end{tabular}

\section{KESIMPULAN}

Ilustrasi empirik ini menyarankan bahwa teknologi gas buang rumah tangga ramah lingkungan dapat secara efisien dibobotkan menggunakan metode AHP/DEA. Sebagai hasil dari pendekatan ini, salah satu teknologi gas buang rumah tangga, yaitu Non-CO2 gas technology, ditemukan lebih efisien dari ke 8 teknologi yang lainnya. Akhirnya dalam makalah ini disimpulkan bahwa pengambil keputusan dan pembuat kebijakan dapat menerapkan prosedur saintifik seperti AHP dan DEA untuk menyelesaikan masalah-masalah MCDM.

\section{DAFTAR PUSTAKA}

1. Charnes, A., Cooper, W.W., Rhodes, E., (1978). "Measuring the efficiency of decision making units", European Journal of Operations Research, vol. 2, no. 6, pp. 429-444.

2. Lee, S.K., Yoon, Y.J., dan Kim J.W., (2007). "Long-term improvements in national energy efficiency and GHG control plans using the AHP approach", Energy policy, vol. 35 , no. 5, pp. $2862-$ 2868.

3. Saaty, T.L., (1980). The Analytic Hierarchy Process, first ed. McGrawHill, New York.

4. Saaty, T.L., (1986). "Exploring Optimization Through Hierarchies and Ratio Scales", Socio- Economic Planning Sciences, vol. 20, no. 6, pp. 355-363.

5. Vitner, G., Rozenes, S., Spraggett, S., (2006). "Using data envelope analysis to compare project efficiency in a multiproject environment", International Journal of Project Management, vol. 24, pp. 323-329. 